\title{
A Comparative Study of the Adsorption of Methylene Blue onto Synthesized Nanoscale Zero-Valent Iron-Bamboo and Manganese-Bamboo Composites
}

\author{
Solomon E. Shaibu ${ }^{1}$, Folahan A. Adekola ${ }^{1}$, Halimat I. Adegoke ${ }^{1}$ and Olushola S. Ayanda ${ }^{2, *}$ \\ 1 Department of Chemistry, University of Ilorin, P.M.B 1515, Ilorin 240222, Nigeria; \\ E-Mails: shaibusolomon@gmail.com (S.E.S.); faadekola@yahoo.fr (F.A.A.); \\ ihalimat@yahoo.com (H.I.A.) \\ 2 Environmental and Nano Science Research Group, Department of Chemistry, University of the \\ Western Cape, Private Bag X17, Bellville 7535, South Africa \\ * Author to whom correspondence should be addressed; E-Mail: osayanda@gmail.com; \\ Tel.: +234-805-464-2362.
}

Received: 1 April 2014; in revised form: 13 May 2014 / Accepted: 23 May 2014 /

Published: 12 June 2014

\begin{abstract}
In this study, bamboo impregnated with nanoscale zero-valent iron (nZVI) and nanoscale manganese $(\mathrm{nMn})$ were prepared by the aqueous phase borohydride reduction method and characterized using scanning electron microscopy (SEM), Fourier transform infrared spectroscopy (FTIR) and PIXE analysis. The synthesized nMn-bamboo and nZVI-bamboo composites were subsequently applied to the sorption of methylene blue (MB) dye from aqueous solution. The adsorption of $\mathrm{MB}$ dye was investigated under various experimental conditions such as $\mathrm{pH}$, contact time, initial concentration of $\mathrm{MB}$ dye and adsorbent dosage. The results showed that the synthesized nZVI-bamboo composite was more effective than nMn-bamboo composite in terms of higher MB dye adsorption capacity of $322.5 \mathrm{mg} / \mathrm{g}$ compared to $263.5 \mathrm{mg} / \mathrm{g}$ of nMn-bamboo composite. At a concentration of $140 \mathrm{mg} / \mathrm{L} \mathrm{MB}$ dye, $0.02 \mathrm{~g}$ of nZVI-bamboo and nMn-bamboo composites resulted in $79.6 \%$ and $78.3 \%$ removal, respectively, at $165 \mathrm{rpm}$, contact time of $120 \mathrm{~min}$ and at a solution $\mathrm{pH}$ of 7.6. The equilibrium data was best represented by Freundlich isotherm model and the pseudo-second order kinetic model better explained the kinetic data for both nZVI-bamboo and nMn-bamboo composites.
\end{abstract}

Keywords: bamboo; nanoscale zero-valent iron (nZVI); nanoscale manganese (nMn); methylene blue dye; adsorption 


\section{Introduction}

Rapid industrialization and urbanization have resulted in the generation of large quantities of aqueous effluents, many of which contain high levels of toxic pollutants such as dyes, persistent organic pollutants (POPs), heavy metals etc. [1,2]. Dyes are highly colored polymers with low biodegradability and are highly recalcitrant, persist for long distances in flowing water, retard photosynthetic activity, inhibit the growth of aquatic biota by blocking out sunlight and utilizing dissolved oxygen, and also decrease the recreation value of stream. Almost every industry uses coloring matter to color their products. The total dye consumption of the textile industries alone is in excess of $10^{7} \mathrm{~kg} /$ year and an estimated $90 \%$ of this total ends up on fabric [3]. Consequently, approximately $106 \mathrm{~kg} / \mathrm{year}$ of dyes are discharged into the waste streams by textile industries. Dye industry effluents constitute one of the most problematic wastewaters to be treated not only for their high chemical and biological oxygen demands (BOD) and suspended solid and content in the toxic compounds but also for their aesthetic impact [4]. Over the years, various methods of wastewater treatment have been reported and adsorption is one of the most widely accepted techniques in terms of its cost effectiveness, versatility, simplicity and ease of operation [5-7]. The use of nanoscale composite materials has been reported over the years by quite a number of researchers for the treatment of wastewater. Some include the remediation of tributyltin using $\mathrm{nFe}_{3} \mathrm{O}_{4}$, activated carbon and $\mathrm{nFe}_{3} \mathrm{O}_{4}$ /activated carbon composite material reported by Ayanda et al. [8], the synthesis of supported nanoscale zero-valent iron (nZVI) was reported by Zhang et al. [9] where nZVI supported on exfoliated graphite was used for the removal of nitrate. Sheela et al. [10] and Rahmani et al. [11] investigated the adsorption of heavy metals onto nanoscale zinc oxide (nZnO) and alumina, respectively. In addition, Frost et al. [12] used palygorskite supported zero-valent iron for the removal of methylene blue (MB) and Shahryari et al. [13] reported the adsorption of MB onto carbon nanotubes. However, no work has been reported on the use of nZVI- and nanoscale manganese (nMn)-bamboo composites for the removal of $\mathrm{MB}$ from aqueous solution. Bamboo is a low cost agricultural waste material, readily available, and its composition with nZVI and nMn will improve some of its physicochemical properties and also serve as a means for conversion of the agricultural waste (bamboo) to economical use, through its application in the removal of MB. Moreover, bamboo supported nZVI because of the need to overcome some of the disadvantages inherent in the use of nZVI which reduces its efficiency and usability, such as rapid oxidation, a strong tendency to agglomerate into larger particles and also the separation and recovery of the fine particles after usage.

The objective of this research is to evaluate the effectiveness of synthesized nZVI-bamboo and nMn-bamboo composites for the removal of MB as a model compound for basic dyes. The effects of $\mathrm{pH}$, contact time, initial dye concentration and adsorbent dosage on adsorption capacity will be investigated. In the same vein, equilibrium and kinetic models will be used to fit the experimental data and the equilibrium and kinetic constants determined. Results from this study can be used to assess the utility of nZVI-bamboo and nMn-bamboo composites for dyes removal, in particular MB adsorption, at the field scale. 


\section{Results and Discussion}

\subsection{Scanning Electron Microscopy (SEM)}

The SEM images of the synthesized nZVI, nMn, bamboo, nZVI-bamboo and nMn-bamboo composites are presented in Figure 1. The SEM image of nZVI in Figure 1b showed agglomeration of the iron nanoparticles, the size of which might be in micron rather than existing as separate nanoparticles. This is similar to what was earlier reported by Çelebi et al. [14], and as can be observed from the SEM images, the synthesized nZVI and nMn particles in Figure 1b,c respectively, were aggregated which is caused by the large surface area and magnetic dipole-dipole interactions of the individual particles as reported by Li et al. [15].

Figure 1. SEM images of (a) Bamboo powder (mag 5000×); (b) nZVI (mag 1000×); (c) nMn (mag 1000×); (d) nZVI-bamboo composite (mag 1000×); and (e) nMn-bamboo composite (mag 1000×).

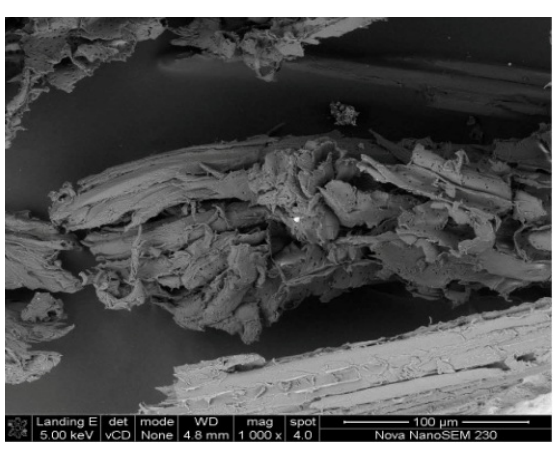

(a)

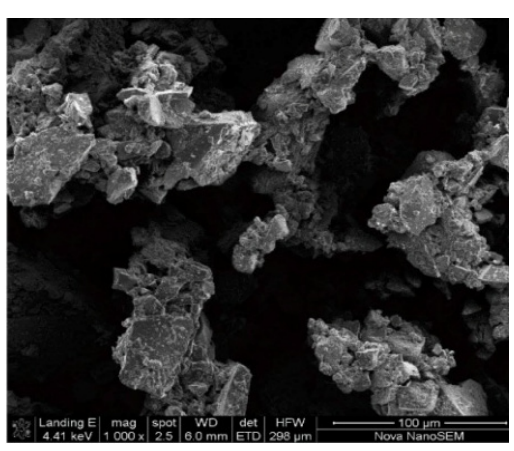

(b)

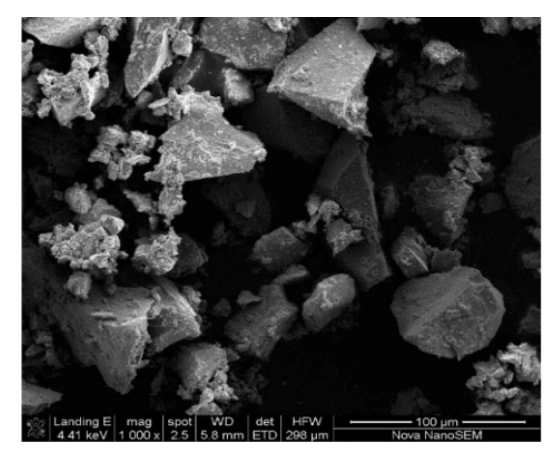

(c)

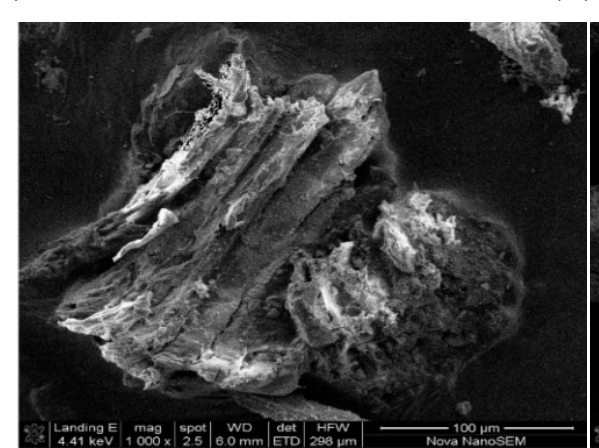

(d)

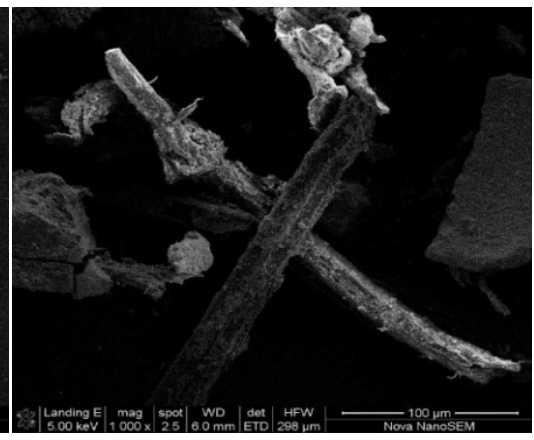

(e)

The micrographs of the bamboo and nZVI-bamboo are also shown in Figure 1a,d, respectively, and aggregation was also observed in the nZVI-bamboo composite due to synthesis at ambient conditions which is also similar to that observed in nMn-bamboo composite in Figure 1e. In addition, the SEM image of nZVI-bamboo composite similar to that of nMn-bamboo composite (Figure 1d,e) showed that the bamboo fibre was completely surrounded by the nanoparticles. The nMn particles in Figure 1c were evenly distributed on the surface of the bamboo fibres, thereby increasing the surface area of the nMn-bamboo composite. Also, the pores and crevices on the surface of the bamboo fibre have been filled with the nanoscale iron and manganese particles due to their comparatively smaller sizes. 


\subsection{Fourier Transform Infrared Spectroscopy (FTIR)}

The FTIR spectra of bamboo, nZVI, nMn, nZVI-bamboo and nMn-bamboo are presented in the supplementary document, Figures S1-S5. The FTIR spectra of bamboo show a strong broad O-H stretching absorption at $3417.98 \mathrm{~cm}^{-1}$ and a prominent $\mathrm{C}-\mathrm{H}$ stretching absorption around $2939.61 \mathrm{~cm}^{-1}$. The non-conjugated $\mathrm{C}-\mathrm{O}$ stretch (in hemicellulose) was observed at $1728.28 \mathrm{~cm}^{-1}$, and the aromatic skeletal vibration in lignin appeared at $1604.83 \mathrm{~cm}^{-1}$. There was also a stronger carbonyl band at $1728.28 \mathrm{~cm}^{-1}$, indicating relatively high-xylan content present in bamboo. Due to the composition of $\mathrm{nMn}$ and nZVI with the bamboo, some prominent peaks could be seen among the absorption bands of nMn-bamboo and nZVI-bamboo composites, such as those at $3441.12 \mathrm{~cm}^{-1}, 1728.28 \mathrm{~cm}^{-1}, 1639.55 \mathrm{~cm}^{-1}$, $1604.83 \mathrm{~cm}^{-1}$, due to $\mathrm{O}-\mathrm{H}$ stretching, non-conjugated $\mathrm{C}-\mathrm{O}$, conjugated $\mathrm{C}=\mathrm{O}$ in lignin, and aromatic skeletal vibration in lignin, respectively. The FTIR spectrum of nZVI-bamboo composite is similar to that of nMn-bamboo composite except for some little band differences as shown in Table 1.

Table 1. Diagnostic bands of bamboo, nMn, nMn-bamboo, nZVI, and nZVI-bamboo composite.

\begin{tabular}{ccccc}
\hline Bamboo $\left(\mathbf{c m}^{\mathbf{- 1}}\right)$ & $\mathbf{n M n}\left(\mathbf{c m}^{\mathbf{- 1}}\right)$ & $\mathbf{n M n}-$ Bamboo $\left(\mathbf{c m}^{-\mathbf{1}}\right)$ & $\left.\mathbf{n Z V I ~} \mathbf{( c m}^{-\mathbf{1}}\right)$ & $\mathbf{n Z V I - B a m b o o}\left(\mathbf{c m}^{\mathbf{- 1}}\right)$ \\
\hline 3417.98 & 3404.47 & 3417.98 & 3421.83 & 3441.12 \\
2939.61 & - & 2895.25 & - & 2899.11 \\
1728.28 & - & 1726.35 & - & 1728.28 \\
1604.83 & 1629.9 & 1604.83 & 1637.62 & 1639.55 \\
\hline
\end{tabular}

\subsection{Particle Induced X-ray Emission (PIXE)}

The elements present ranging from $\mathrm{Si}$ to $\mathrm{Zn}$ are shown in Table 2. The concentration of some metals in nMn-bamboo composite, such as $\mathrm{Al}, \mathrm{Si}, \mathrm{Ti}, \mathrm{Zn}, \mathrm{Ni}$, and $\mathrm{Mn}$ decreased while those of $\mathrm{K}, \mathrm{Ca}$ and Fe were higher compared to that of nMn while in the case of nZVI-bamboo composite, an increase was observed in the concentration of $\mathrm{Al}, \mathrm{K}, \mathrm{Ca}, \mathrm{Cr}$ and $\mathrm{Zn}$ which might be due to the concentrations of $\mathrm{FeCl}_{3}, \mathrm{MnCl}_{4} \cdot \mathrm{H}_{2} \mathrm{O}$ and $\mathrm{NaBH}_{4}$ used in the preparation of the composites. Chromium (Cr) and nickel (Ni) were absent in nMn-bamboo and nZVI-bamboo composites, respectively.

Table 2. Concentration of elements in bamboo, nMn, nMn-bamboo, nZVI, and nZVI-bamboo composite by PIXE analysis.

\begin{tabular}{cccccc}
\hline \multirow{2}{*}{ Symbol } & \multicolumn{5}{c}{ Concentration $(\mathbf{m g} / \mathbf{L})$} \\
\cline { 2 - 6 } & Bamboo & nMn & nMn-Bamboo & nZVI & nZVI-Bamboo \\
\hline $\mathrm{Al}$ & 4696.8 & $23,563.1$ & 7369.7 & $10,785.7$ & $12,088.1$ \\
$\mathrm{Si}$ & 3047.1 & 8755.9 & 3485.9 & $12,516.6$ & 2161.0 \\
$\mathrm{Cl}$ & 289.1 & $64,805.2$ & $46,723.5$ & $20,680.3$ & $16,791.6$ \\
$\mathrm{~K}$ & 72.3 & $\mathrm{nd}$ & 62.6 & 76.0 & 79.8 \\
$\mathrm{Ca}$ & 110.6 & 261.1 & 345.4 & 335.0 & 598.8 \\
$\mathrm{Ti}$ & 9.5 & 60.8 & 35.4 & 123.9 & 89.8 \\
$\mathrm{Cr}$ & 13.0 & $\mathrm{nd}$ & $\mathrm{nd}$ & 68.8 & 83.5 \\
$\mathrm{Mn}$ & 37.5 & $336,339.4$ & $109,879.9$ & 1584.7 & 747.7 \\
$\mathrm{Fe}$ & 363.8 & 3889.4 & 4232.2 & $331,691.0$ & $179,229.8$ \\
$\mathrm{Ni}$ & $\mathrm{nd}$ & 320.1 & 48.0 & $\mathrm{nd}$ & $\mathrm{nd}$ \\
$\mathrm{Zn}$ & 7.3 & 155.4 & 93.4 & $\mathrm{nd}$ & 2.4 \\
\hline
\end{tabular}

nd-not detected (represents concentration that are below the detection level of the machine). 


\subsection{Effect of Initial Concentration}

The initial concentration provides an important driving force in order to overcome all mass transfer resistance of the dye between the aqueous and the solid phase. The percent removal of MB for both composite materials decreases with an increase in initial concentration as shown in Figure 2, suggesting that at lower MB concentration, there were many vacant adsorption sites available for the $\mathrm{MB}$ molecules to attach to until the surface of the adsorbents was saturated at $140 \mathrm{mg} / \mathrm{L}$ where the amount of MB adsorbed did not increase significantly. In addition, the percentage removal of MB dye decreased from $92.3 \%$ to $63.3 \%$ using nZVI-bamboo composite while that of nMn-bamboo composite decreased from $80.1 \%$ to $40.8 \%$ as the initial concentration of MB dye increased from 10 to $160 \mathrm{mg} / \mathrm{L}$. Similar findings were reported by Shirmadi et al. [16].

Figure 2. Effect of initial methylene blue $(\mathrm{MB})$ concentration $(w t=0.02 \mathrm{~g}, \mathrm{pH}=5$, $T=32 \pm 2{ }^{\circ} \mathrm{C}$ for $2 \mathrm{~h}$ at $\left.165 \mathrm{rpm}\right)$.

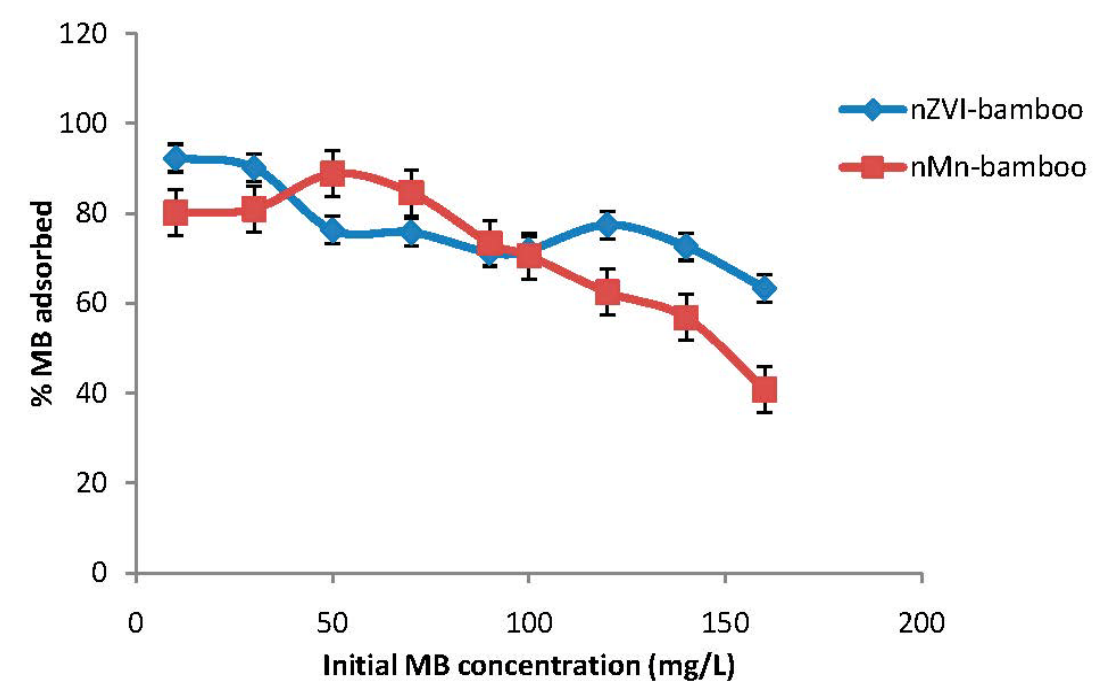

\subsection{Effect of Adsorbent Dosage}

The amount of available surface area under an effectively constant metal surface is one of the most significant experimental variables affecting contaminant reduction rate. The effect of adsorbent dosage on MB sorption is shown in Figure 3 and it followed the predicted pattern of an increasing percentage adsorbed as the dosage of the different adsorbents increases. The removal of MB increased from $62.4 \%$ to $76.3 \%$ and $40.7 \%$ to $73.7 \%$ for nZVI-bamboo and nMn-bamboo composites, respectively, which could be as a result of an increase in the surface area and availability of more adsorption sites as the dosage increased, which is similar to the report of Cengiz and Cavas [17].

\subsection{Effect of Initial $\mathrm{pH}$}

The solution $\mathrm{pH}$ would affect both aqueous chemistry and surface binding sites of the adsorbents. So, the $\mathrm{pH}$ is an important parameter in the dye adsorption process [18]. The hydrogen ion concentration $(\mathrm{pH})$ primarily affects the degree of ionization of the dyes and the surface properties of the adsorbent. As can be seen from Figure 4, the adsorption of MB dye onto nZVI-bamboo and nMn-bamboo composites 
is highly dependent on the initial $\mathrm{pH}$ of solution. Higher removal percentages of $\mathrm{MB}$ dye from solution was observed for nZVI-bamboo and nMn-bamboo composites at $\mathrm{pH} 11$, being $79.6 \%$ and $78.3 \%$, respectively. The adsorption capacity of $\mathrm{MB}$ increased with increasing solution $\mathrm{pH}$ from 3 to 5 . No significant increase was further noted until $\mathrm{pH} 9$ where a rapid adsorption was observed. This result can be attributed to the effect of the solution $\mathrm{pH}$ on the charge of reactive group within the adsorbents which in turn makes them more effective at adsorbing $\mathrm{MB}$ dye in alkaline $\mathrm{pH}$. A similar observation was reported by $\mathrm{Hu}$ et al. [19] and Salman et al. [20].

Figure 3. Effect of adsorbent dosage $\left(C_{0}=140 \mathrm{mg} / \mathrm{L}, \mathrm{pH}=5, T=32 \pm 2{ }^{\circ} \mathrm{C}\right.$ for $2 \mathrm{~h}$ at $\left.165 \mathrm{rpm}\right)$.

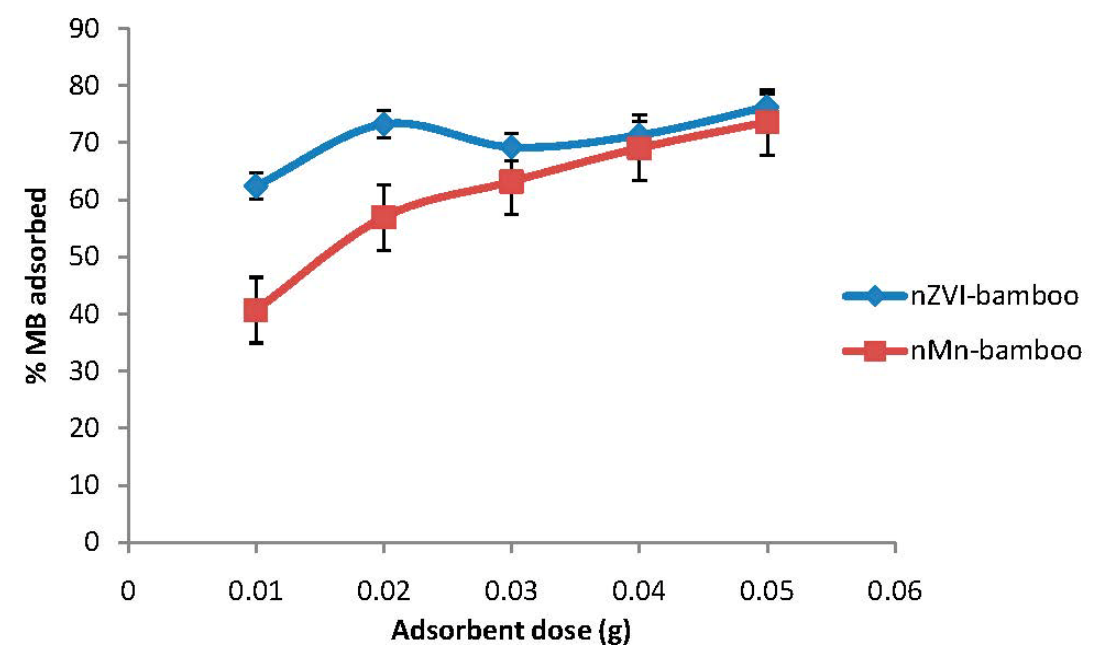

Figure 4. Effect of $\mathrm{pH}\left(w t=0.02 \mathrm{~g}, C_{0}=140 \mathrm{mg} / \mathrm{L}, T=32 \pm 2{ }^{\circ} \mathrm{C}\right.$ for $2 \mathrm{~h}$ at $\left.165 \mathrm{rpm}\right)$.

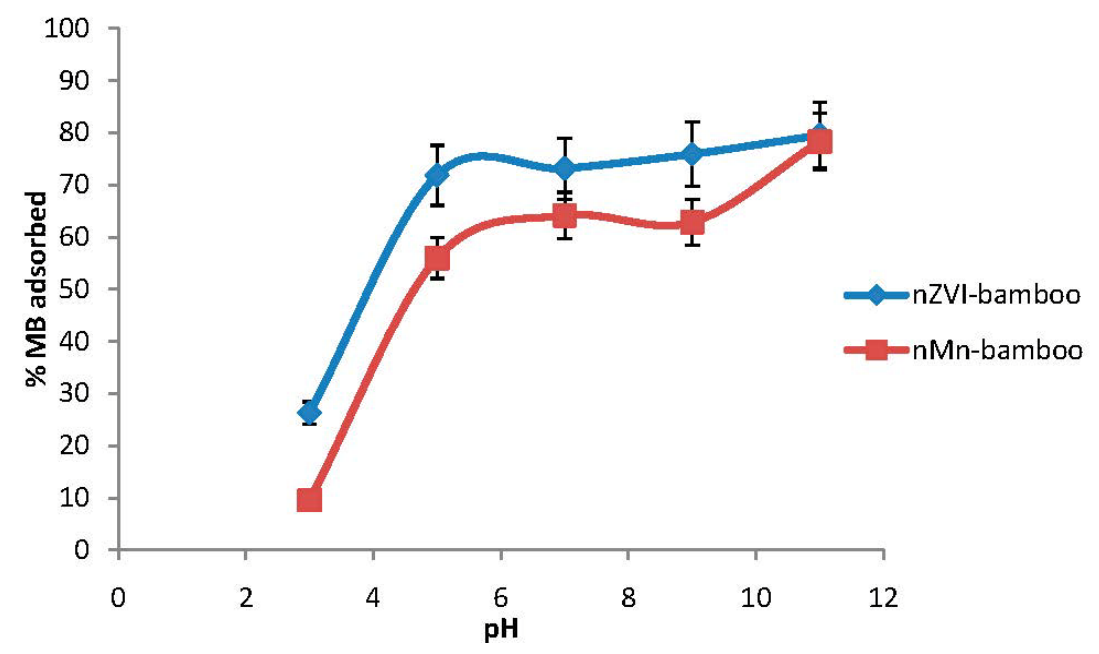

\subsection{Effect of Time}

The graph of the amount of MB adsorbed versus contact time is represented in Figure 5. It revealed that the MB adsorption was fast at the initial stage of the contact period and then became slower near the equilibrium time $(120 \mathrm{~min})$ which is similar to the result reported by Karima et al. [21]. This phenomenon was due to the fact that a large number of vacant surface sites were available for adsorption during the initial stage of the adsorption process. Near the equilibrium, the remaining 
vacant surface sites were difficult to occupy due to, probably, the slow pore diffusion of the MB molecules on the adsorbents (nZVI-bamboo and nMn-bamboo) and the repulsive forces between the solid molecules and the bulk phases.

Figure 5. Effect of time $\left(w t=0.02 \mathrm{~g}, \mathrm{pH}=5 ; C_{0}=140 \mathrm{mg} / \mathrm{L}, T=32 \pm 2{ }^{\circ} \mathrm{C}\right.$ at $\left.165 \mathrm{rpm}\right)$.

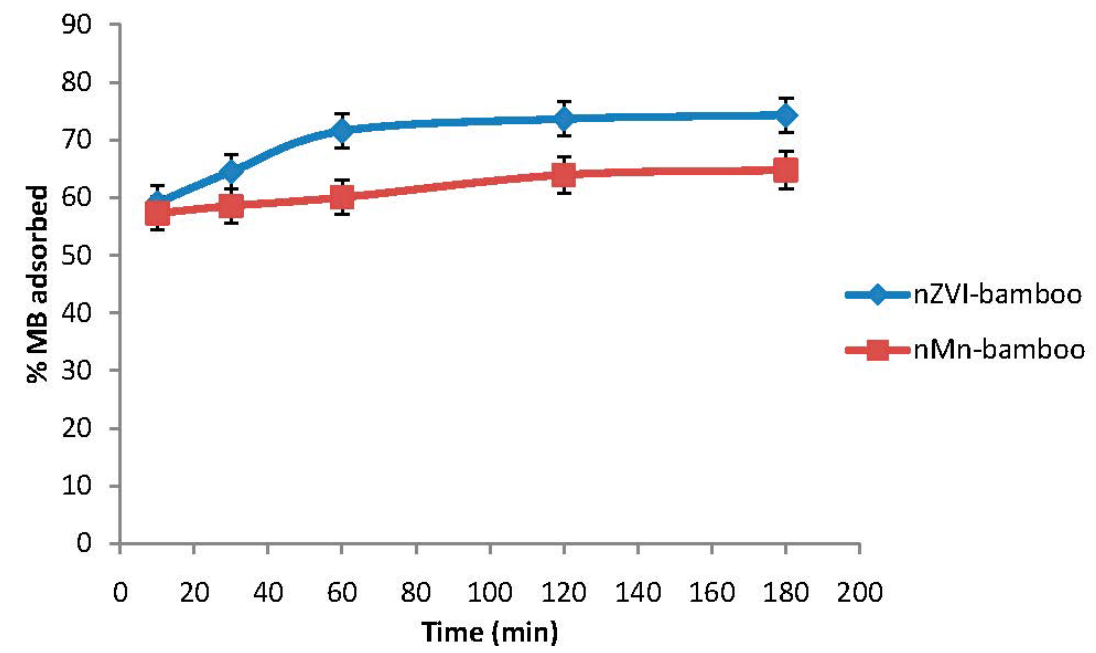

\subsection{Adsorption Isotherm}

The results of the MB concentration dependence study were subjected to analyses by means of Langmuir, Freundlich and Temkin adsorption isotherm models. The Langmuir equation (Equation (1)), which is valid for monolayer sorption on a surface containing a limited number of sites, predicting a homogeneous distribution of sorption energies and the heterogeneity of adsorption deduced from Freundlich equation (Equation (2)). Temkin model (Equation (3)) assumes that heat of adsorption (function of temperature) of all molecules in the layer would decrease linearly rather than logarithmically with coverage.

$$
\begin{gathered}
\frac{c_{\mathrm{e}}}{q_{\mathrm{e}}}=\frac{1}{Q_{\mathrm{o}} b}+\frac{1}{Q_{\mathrm{o}}} c_{\mathrm{e}} \\
\log q_{\mathrm{e}}=\log k_{\mathrm{F}}+\frac{1}{n} \log c_{\mathrm{e}} \\
q_{\mathrm{e}}=\frac{\mathrm{R} T}{b_{T}} \ln A_{T}+\frac{\mathrm{R} T}{b_{T}} \ln c_{\mathrm{e}}
\end{gathered}
$$

where $C_{\mathrm{e}}$ is the equilibrium concentration of the adsorbate $(\mathrm{mg} / \mathrm{L}), q_{\mathrm{e}}$ the amount of adsorbate adsorbed per unit mass of adsorbate $(\mathrm{mg} / \mathrm{g}), Q_{\mathrm{o}}$ and $b$ are Langmuir constants related to adsorption capacity and rate of adsorption, respectively. $k_{\mathrm{F}}$ and $\mathrm{n}$ are Freundlich constants, an indication of how favorable the adsorption process is and $k_{\mathrm{F}}$ is the adsorption capacity of the adsorbent, $A_{T}$ is Temkin isotherm equilibrium binding constant $(\mathrm{L} / \mathrm{g}), b_{T}$ is Temkin isotherm constant $(\mathrm{J} / \mathrm{mol}), \mathrm{R}$ is universal gas constant $(8.314 \mathrm{~J} / \mathrm{mol} / \mathrm{K})$ and $T$ is the absolute temperature.

The adsorption data of nZVI-bamboo and nMn-bamboo composites were adequately interpreted by Freundlich and Langmuir isotherms, respectively based on their regression coefficient (Figure 6 and Table 3). 
Figure 6. (a) Langmiur; (b) Freundlich; and (c) Temkin Isotherms for the adsorption of MB onto nZVI-bamboo and nMn-bamboo composites.
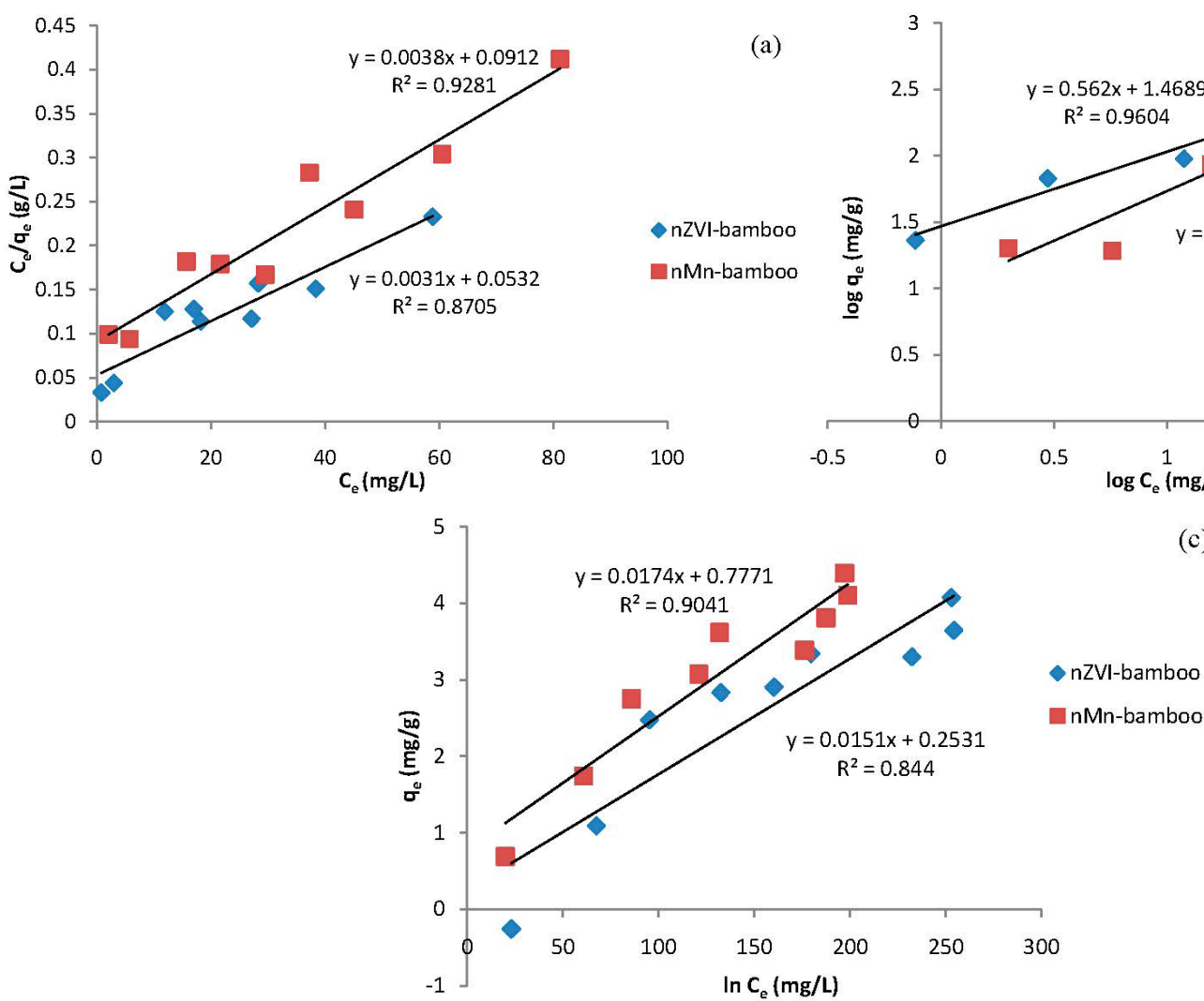

(b)

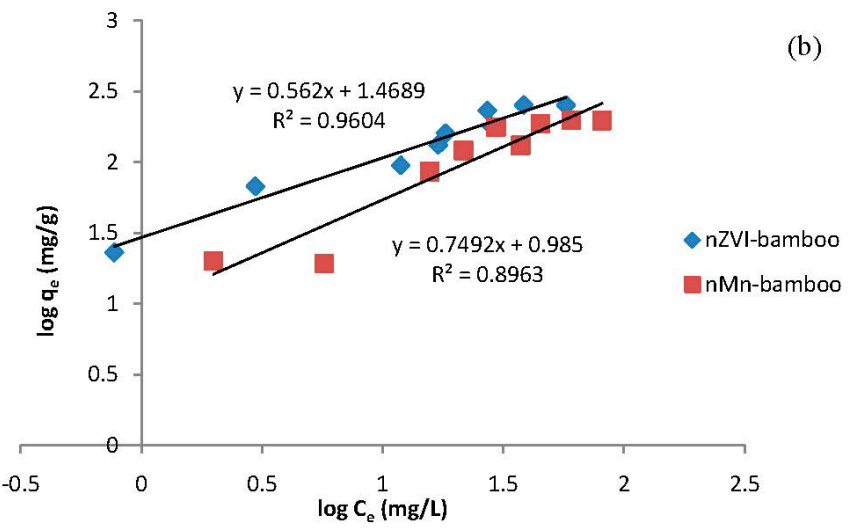

(c)

Table 3. Isotherm parameters for the adsorption of MB onto nMn-bamboo and nZVI-bamboo composites.

\begin{tabular}{cccc}
\hline \multirow{2}{*}{ Isotherm } & \multirow{2}{*}{ Parameters } & \multicolumn{2}{c}{ Values } \\
\cline { 2 - 4 } & & (nMn-bamboo) & (nZVI-bamboo) \\
\cline { 2 - 4 } Freundlich & $K_{\mathrm{F}}\left(\mathrm{mg} / \mathrm{g}(\mathrm{L} / \mathrm{mg})^{1 / n}\right)$ & 9.66 & 29.4 \\
& $n$ & 1.33 & 1.78 \\
& $R^{2}$ & 0.8963 & 0.9604 \\
\hline \multirow{3}{*}{ Langmuir } & $Q_{\mathrm{o}}(\mathrm{mg} / \mathrm{g})$ & 263.2 & 322.6 \\
& $b(\mathrm{~L} / \mathrm{mg})$ & 0.0417 & 0.0583 \\
& $R_{\mathrm{L}}$ & 0.13 & 0.097 \\
& $R^{2}$ & 0.9281 & 0.8705 \\
Temkin & $A_{T}(\mathrm{~L} / \mathrm{g})$ & 1.69 & 1.20 \\
& $b_{T}(\mathrm{~J} / \mathrm{mol})$ & 43.9 & 40.7 \\
& $R^{2}$ & 0.9041 & 0.844 \\
\hline
\end{tabular}

The adsorption is evidently favorable from the value of the Freundlich constant $n$ which is 1.901 and 1.335 while the constant $k_{\mathrm{F}}$ has a value of 29.437 and 9.66 for nZVI-bamboo composite and nMn-bamboo, respectively, indicative of the affinity of the MB dye and the composite materials. The good agreement of Langmuir's isotherm with the adsorption data may be due to homogeneous distribution of active sites on the nMn-bamboo composite, since the Langmuir equation (Equation (1)) assumes that the surface is homogeneous. The values of the adsorption coefficient $b$ and the monolayer capacity $Q_{0}$ calculated from Langmuir equation (Equation (1)) is given in Table 3. 
To know the feasibility of this isotherm, the essential features of Langmuir model can be expressed in terms of $\mathrm{R}_{\mathrm{L}}$. The values of $\mathrm{R}_{\mathrm{L}}$ indicate the shapes of isotherms to be either unfavorable $\left(R_{\mathrm{L}}>1\right)$, linear $\left(R_{\mathrm{L}}=1\right)$, favorable $\left(0<R_{\mathrm{L}}<1\right)$ or irreversible $\left(R_{\mathrm{L}}=0\right)$ [22]. The calculated $R_{\mathrm{L}}$ values $(0.13$ and 0.096$)$ show that the adsorption of MB onto nZVI-bamboo and nMn-bamboo composite is favorable.

Table 4 shows the saturated adsorption capacities of MB for ZVI-bamboo and nMn-bamboo composites along with some other adsorbents in literature. It could be clearly seen that nZVI-bamboo and nMn-bamboo composites exhibited higher saturated adsorption capacity, which could be ascribed to their larger surface area and numerous pores compared to other adsorbents listed in Table 4.

Table 4. Saturated adsorption capacities of MB for some adsorbents.

\begin{tabular}{ccc}
\hline Adsorbent & Saturated Adsorption Capacity $(\mathbf{m g} / \mathbf{g})$ & References \\
\hline Zeolite & 16.37 & {$[23]$} \\
CTNTs & 133.33 & {$[24]$} \\
Activated sewage char & 120.00 & {$[25]$} \\
Raw date pits & 80.29 & {$[26]$} \\
nMn-bamboo & 263.2 & Present work \\
nZVI-bamboo & 322.6 & Present work \\
\hline
\end{tabular}

\subsection{Kinetic Models}

To study the kinetics of the adsorption of MB onto nZVI-bamboo and nMn-bamboo composites, three different kinetic models were used for the analysis of the adsorption data of each of the adsorbents, viz: pseudo-first order (Equation (4)), pseudo-second order (Equation (5)) and Elovich (Equation (6)) models.

$$
\begin{gathered}
\log \left(q_{\mathrm{e}}-q_{t}\right)=\log q_{\mathrm{e}, \mathrm{cal}}-\frac{k_{1}}{2.303}(t) \\
\frac{t}{q_{t}}=\frac{1}{k_{2} q_{\mathrm{e}, \mathrm{cal}}{ }^{2}}+\frac{1}{q_{\mathrm{e}, \mathrm{cal}}}(t) \\
q_{t}=\frac{1}{\beta} \ln \frac{\alpha_{\mathrm{E}}}{\beta}+\frac{1}{\beta} \ln t
\end{gathered}
$$

where $k_{1}, k_{2}, \alpha_{\mathrm{E}}$, and $\beta$, are the pseudo first-order, pseudo second-order and Elovich constants, respectively.

Evidently, the adsorption data fitted the pseudo-second order kinetic model with regression coefficients of 0.9995 and 0.9998 for nZVI-bamboo and nMn-bamboo composites, respectively than pseudo-first order and Elovich models which also show a fairly good interpretation of the adsorption data as shown in Figure 7 and Table 5.

Experimental results thus revealed that the support (bamboo) stabilizes the nZVI and nMn particles and the mass transfer of MB to nZVI surfaces was promoted because of the adsorption by the support. These prevent the agglomeration of nZVI during adsorption and eventually enhance the efficiency of these materials to remove MB dyes [27,28]. Moreover, bamboo is readily available in our environment as waste while nanoparticles are expensive due to various instrumental techniques that are required to inform us about the properties of the synthesized nanoparticles. A combination of bamboo with 
nanoparticles will reduce the cost of using only nanoparticles for the remediation of organic pollutants and will lead to improvements in the physicochemical properties of the formed composite.

Figure 7. (a) Pseudo-first order; (b) pseudo-second order; and (c) Elovich models for the adsorption of MB onto nZVI-bamboo and nMn-bamboo composites.
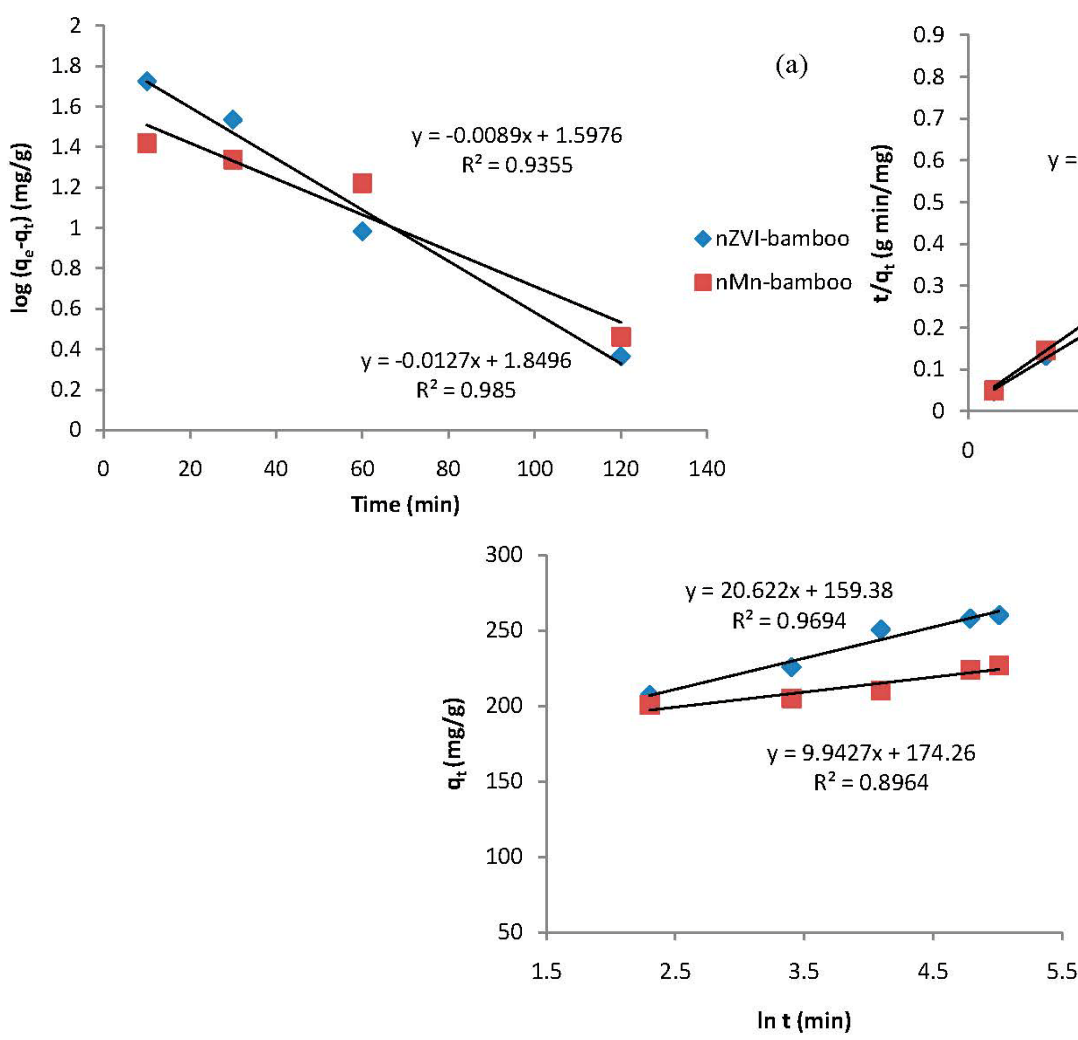

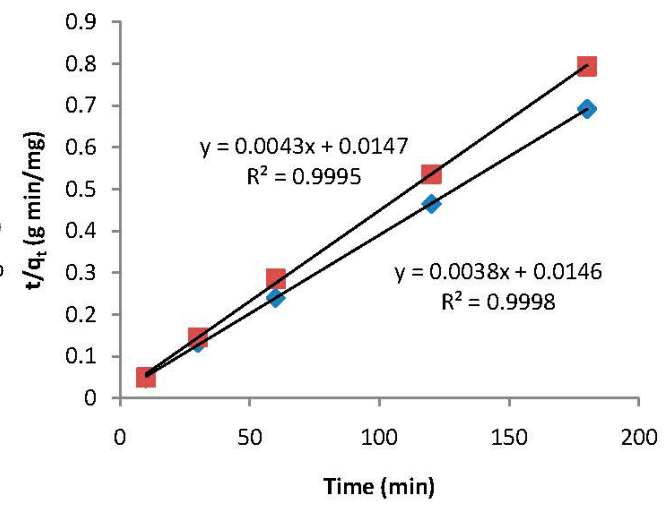

(c)

(b)

nZVI-bamboo

nMn-bamboo

จ nZVI-bamboo

nMn-bamboo

Table 5. Parameters and correlation coefficients of the kinetic models for nMn-bamboo and nZVI-bamboo composites.

\begin{tabular}{cccc}
\hline \multirow{2}{*}{ Kinetic Models } & \multirow{2}{*}{ Parameters } & \multicolumn{2}{c}{ Values } \\
\cline { 3 - 4 } & $k_{1}\left(\mathrm{~min}^{-1}\right)$ & 0.0205 & 0.0290 \\
Pseudo-first order & $q_{\mathrm{e}, \mathrm{cal}}(\mathrm{mg} / \mathrm{g})$ & 39.6 & 70.7 \\
& $R^{2}$ & 0.9350 & 0.9850 \\
\hline \multirow{3}{*}{ Pseudo-second order } & $k_{2}(\mathrm{~g} / \mathrm{mg} / \mathrm{min})$ & 0.0013 & 0.0009 \\
& $q_{\mathrm{e}, \mathrm{cal}}(\mathrm{mg} / \mathrm{g})$ & 232.56 & 263.16 \\
& $R^{2}$ & 0.9995 & 0.9998 \\
\hline \multirow{2}{*}{ Elovich } & $\beta(\mathrm{g} \cdot \mathrm{min} / \mathrm{mg})$ & 0.0485 & 0.1006 \\
& $\alpha_{\mathrm{E}}\left(\mathrm{g} \cdot \mathrm{min}^{2} / \mathrm{mg}\right)$ & $4.69 \times 10^{3}$ & $4.09 \times 10^{8}$ \\
& $R^{2}$ & 0.8964 & 0.9694 \\
\hline
\end{tabular}

\section{Experimental Section}

\subsection{Reagents}

Analytical grade iron (III) chloride (Sigma Aldrich, Diegem, Belgium), manganese (IV) chloride (Minimum assay 99.9\%, Tianjin Kermel, Hebei, China), sodium borohydride (BDH 95\%, prd No. 30114, 
Sigma Aldrich, Diegem, Belgium), MB dye (BDH prd No. 340484B, Sigma Aldrich, Diegem, Belgium), absolute ethanol (BDH Analar, 95\% UN No. 1097, Sigma Aldrich, Diegem, Belgium), hydrochloric acid (Purity 37\%, density $1.1 \mathrm{~kg} / \mathrm{cm}^{3}$, Riedel-deHaen, Buffalo, NY, USA) and sodium hydroxide (BDH prod. No. 30167, Sigma Aldrich, Diegem, Belgium) were used without further purification. Other basic laboratory glass-wares and apparatus were also used in the course of this research.

\section{2. nZVI-Bamboo Composite Preparation}

The nZVI-bamboo composite was prepared by borohydride reduction method with $\mathrm{FeCl}_{3}$ and bamboo in the ratio 1:1. The reduction method was related to the method reported by Yuvakkumar et al. [29]. A $0.8111 \mathrm{~g}$ of treated bamboo (i.e., the bamboo was washed with $0.1 \mathrm{M} \mathrm{HCl}$ solution, dried and ground into fine powder) was weighed and added into a solution of $0.05 \mathrm{M} \mathrm{FeCl}_{3}$ in a beaker and stirred on a magnetic stirrer for $2 \mathrm{~h}$ to ensure thorough mixture of both materials and then poured into a three neck flask before addition of the borohydride solution. A $0.53 \mathrm{M} \mathrm{NaBH}_{4}$ solution was added into the beaker containing the mixture of the bamboo and $\mathrm{FeCl}_{3}$ solution. After the complete addition of the borohydride solution, the resulting mixture was further stirred for another $30 \mathrm{~min}$. The resulting precipitate was washed several times with ethanol and filtered through $0.45 \mu \mathrm{m}$ millipore filter paper by vacuum filtration technique and was oven dried at $50{ }^{\circ} \mathrm{C}$ overnight [12].

\section{3. nMn-Bamboo Composite Preparation}

The nMn-bamboo composite was also prepared by borohydride reduction method similar to that of nZVI-bamboo composite with $\mathrm{MnCl}_{4} \cdot \mathrm{H}_{2} \mathrm{O}$ and bamboo in the ratio 1:1. A $1.979 \mathrm{~g}$ of the treated bamboo was weighed and added into a solution of $0.05 \mathrm{M} \mathrm{MnCl}_{4} \cdot \mathrm{H}_{2} \mathrm{O}$ in a beaker and stirred on a magnetic stirrer for $2 \mathrm{~h}$ to ensure thorough mixture of both materials and then poured into a three neck flask before addition of the borohydride solution. A $0.53 \mathrm{M} \mathrm{NaBH}_{4}$ solution was added into the beaker containing the mixture of the bamboo and $\mathrm{MnCl}_{4} \cdot \mathrm{H}_{2} \mathrm{O}$ solution. After the complete addition of the borohydride solution, the resulting mixture was further stirred for another $30 \mathrm{~min}$. The resulting precipitate was subjected to similar filtration and drying process as that of nZVI-bamboo composite. Figure 8 shows the schematic diagram for the synthesis of nZVI-bamboo and nMn-bamboo composites.

Figure 8. Schematic diagram for the synthesis of nZVI-bamboo and nMn-bamboo composites.

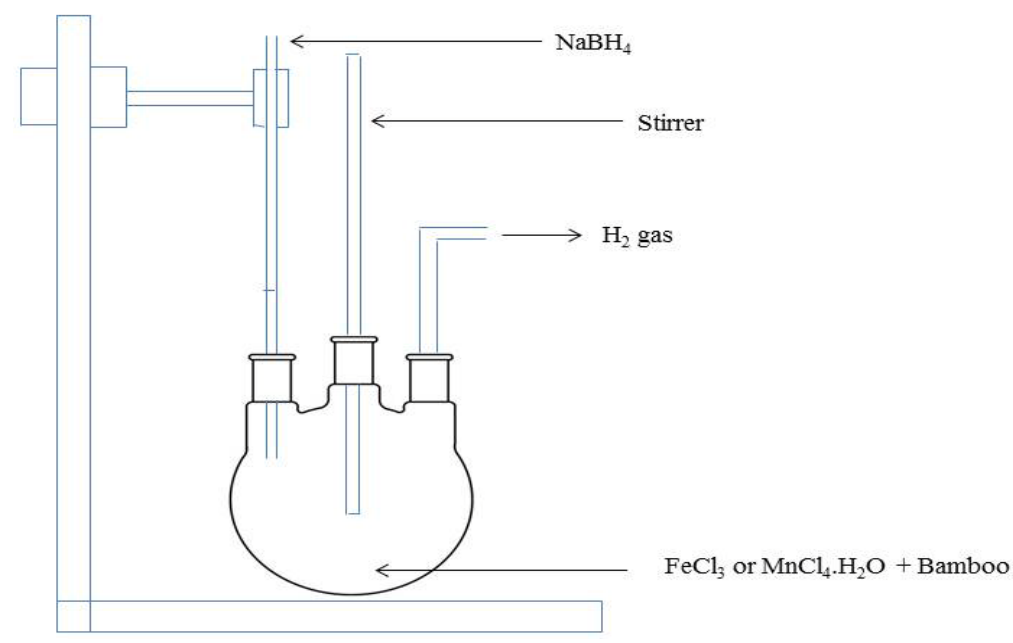




\subsection{Characterization of nZVI-Bamboo and nMn-Bamboo Composites}

The scanning electron micrograph (SEM) of nZVI, nMn, bamboo, nZVI-bamboo and nMn-bamboo composites was viewed under a $\mathrm{FEI}^{\mathrm{TM}}$ scanning electron microscope (Nova Nano SEM 230, FEI, Hillsboro, OR, USA). A $1.7 \mathrm{MV}$ 5SDH tandem pelletron accelerator was used to analyze for the concentration of the elements present. Fourier transform infrared spectroscopy (FTIR, Shimadzu, Columbia, MD, USA) absorption spectra were obtained using the potassium bromide (KBr) pellet method and the spectra of the samples were recorded over the range $4000-400 \mathrm{~cm}^{-1}$ using Shimadzu FTIR-8400S.

\subsection{Adsorption Studies}

Dye removal experiments with the synthesized nZVI-bamboo and nMn-bamboo composites were carried out by batch tests in $100 \mathrm{~mL}$ flasks under vigorous agitation at $165 \mathrm{rpm}$. The experiment involved preparing $50 \mathrm{~mL}$ of $\mathrm{MB}$ solution with a desired initial concentration $(140 \mathrm{mg} / \mathrm{L})$ and $\mathrm{pH}$, by diluting the stock dye solutions with deionized water and transferring it into the conical flask for agitation. The $\mathrm{pH}$ of the solution was adjusted using $0.1 \mathrm{M} \mathrm{HCl}$ or $0.1 \mathrm{M} \mathrm{NaOH}$ solutions by a $\mathrm{pH}$ meter model (pH 211 Microprocessor). A $0.02 \mathrm{~g}$ of nZVI-bamboo and nMn-bamboo composites (adsorbent dosage) was then added to different conical flask containing dye solution and the obtained suspensions were immediately agitated for a predefined time of $120 \mathrm{~min}$. After the contact time elapsed, the different suspensions were filtered separately and the filtrates were analyzed using a UV/visible spectrophotometer (UV/vis DU 730, Beckman Coulter, Pasadena, CA, USA) at maximum absorption wavelength of $665 \mathrm{~nm}$ for $\mathrm{MB}$ dye. The amount of $\mathrm{MB}$ adsorbed, $q_{\mathrm{e}}(\mathrm{mg} / \mathrm{g})$ was obtained using Equation (7):

$$
q_{e}=\frac{C_{0}-C_{f}}{W} V
$$

where $C_{0}$ and $C_{f}$ are the initial and final concentrations of $\mathrm{MB}$ dye $(\mathrm{mg} / \mathrm{L})$, respectively. $V$ is the volume of the solution ( $\mathrm{L})$ and $W$ is the mass of adsorbents $(\mathrm{g})$. The $\%$ adsorbed was calculated using Equation (8).

$$
\% \mathrm{MB}=\frac{C_{0}-C_{f}}{C_{0}} \times 100
$$

All tests were performed in triplicate to ensure the reproducibility of the results; the mean of the measurements was reported. Furthermore, all experiments were performed at room temperature $\left(32 \pm 2{ }^{\circ} \mathrm{C}\right)$. The investigated ranges of the experimental variables were as follows: $\mathrm{MB}$ dye concentration $(10-160 \mathrm{mg} / \mathrm{L})$, initial $\mathrm{pH}$ of solution (3-11), adsorbent dosage $(0.01-0.05 \mathrm{~g})$ and contact time of 10-180 min.

\section{Conclusions}

This study confirmed that the nZVI-bamboo and nMn-bamboo composites prepared by the borohydride reduction method were effective for the removal of MB dye from aqueous solution. The results showed that the adsorption is highly influenced by the initial concentration, solution's $\mathrm{pH}$, 
adsorbent dosage and contact time. The adsorption data were adequately interpreted by Freundlich and Langmuir adsorption isotherm for nZVI-bamboo and nMn-bamboo composites, respectively, and the kinetic data were better explained by the pseudo-second order kinetic model for both composite materials. The results of this experimental study are highly useful for the remediation of real industrial effluent or MB dye-laden wastewater.

\section{Acknowledgments}

We acknowledge Miranda Waldron of the Electron Microscope Unit, University of Cape Town for the SEM analysis of the materials.

\section{Author Contributions}

Folahan A. Adekola designed the project, Solomon E. Shaibu conducted the synthesis of the composites and the adsorption studies, while, Halimat I. Adegoke and Olushola S. Ayanda contributed to characterization of the materials and revised the manuscript. All authors contributed to the discussions.

\section{Conflicts of Interest}

The authors declare no conflict of interest.

\section{References}

1. Vijayaraghavan, K.; Yun, Y.S. Bacterial biosorbents and biosorption. Biotechnol. Adv. 2008, 26, 266-291.

2. Xu, F.L.; Jorgensen, S.E.; Shimizu, Y.; Silow, E. Persistent organic pollutants in fresh water ecosystems. Sci. World J. 2013, 2013, 1-2.

3. Hameed, B.H.; Ahmad, A.A.; Aziz, N. Isotherms, kinetics and thermodynamics of acid dye adsorption on activated palm ash. Chem. Eng. J. 2007, 133, 195-203.

4. Zawani, Z.; Chuah Luqman, A.; Thomas, S.Y.C. Equilibrium, kinetics and thermodynamic Studies: Adsorption of remazol black 5 on the palm kernel shell activated carbon (PKS-AC). Eur. J. Sci. Res. 2009, 37, 67-76.

5. Nigam, P.; Banat, I.M.; Singh, D.; Marchant, R. Microbial process for decolorization of textile effluent containing azo, diazo and reactive dyes. Process Biochem. 1996, 31, 435-442.

6. Garg, V.K.; Gupta, R.; Yadav, B.; Kumar, R. Dye removal from aqueous solution by adsorption on treated sawdust. Bioresour. Technol. 2003, 89, 121-124.

7. Fatoki, O.S.; Ayanda, O.S.; Adekola, F.A.; Ximba, B.J. Sorption of triphenyltin chloride to $\mathrm{nFe}_{3} \mathrm{O}_{4}$, fly ash and $\mathrm{nFe}_{3} \mathrm{O}_{4} /$ fly ash composite material in seawater. Clean Soil Air Water 2013, 42, 472-479.

8. Ayanda, O.S.; Fatoki, O.S.; Adekola, F.A.; Ximba, B.J. Remediation of tributyltin contaminated seawater by adsorption using $\mathrm{nFe}_{3} \mathrm{O}_{4}$, activated carbon and $\mathrm{nFe}_{3} \mathrm{O}_{4} /$ activated carbon composite material. Water Air Soil Pollut. 2013, 224, doi:10.1007/s11270-013-1684-0. 
9. Zhang, H.; Jin, Z.; Han, L.; Qin, C. Synthesis of nanoscale zero-valent iron supported on exfoliated graphite for removal of nitrate. Trans. Nonferr. Met. Soc. China 2006, 16, 345-349.

10. Sheela, T.; Arthoba Nayaka, Y.; Viswanatha, R.; Basavanna, S.; Venkatesha, T.G. Kinetics and thermodynamics studies on the adsorption of $\mathrm{Zn}(\mathrm{II}), \mathrm{Cd}(\mathrm{II})$ and $\mathrm{Hg}(\mathrm{II})$ from aqueous solution using zinc oxide nanoparticles. Powder Technol. 2012, 217, 163-170.

11. Rahmani, A.; Zavvar Mousavi, H.; Fazli, M. Effect of nanostructure alumina on adsorption of heavy metals. Desalination 2010, 253, 94-100.

12. Frost, R.L.; Xi, Y.; He, H. Synthesis, characterization of palygorskite supported zero-valent iron and its application for methylene blue adsorption. J. Colloid Interface Sci. 2010, 341, 153-161.

13. Shahryari, Z.; Goharrizi, A.S.; Azadi, M. Experimental study of methylene blue adsorption fromaqueous solutions onto carbon nano tubes. Int. J. Water Res. Environ. Eng. 2010, 2, 016-028.

14. Celebi, O.; Uzum, C.; Shahwan, T.; Erten, H.N. A radiotracer study of the adsorption behavior of aqueous $\mathrm{Ba}(2+)$ ions on nanoparticles of zero-valent iron. J. Hazard. Mater. 2007, 148, 761-767.

15. Li, L.; Fan, M.; Brown, R.C.; van Leeuwen, L. Synthesis, properties, and environmental applications of nanoscale iron-based materials: A review. Crit. Rev. Environ. Sci. Technol. 2006, $36,405-431$.

16. Shirmardi, M.; Mesdaghinia, A.R.; Mahvi, H.; Nasseri, S.; Nabizadeh, R. Kinetics and equilibrium studies on adsorption of acid red 18 (azo dye) using a multiwall carbon nanotube (MWCNTs) from aqueous solution. E J. Chem. 2012, 9, 476-484.

17. Cengiz, S.; Cavas, L. Removal of methylene blue by invasive marine seaweed: Caulerparacemosa var. cylindracea. Bioresour. Technol. 2008, 99, 2357-2363.

18. Bazrafshan, E.; Mostafapour, F.K.; Hosseini, A.R.; Khorshid, A.R.; Mahvi, A.H. Decolourisation of reactive red 120 dye using single walled carbon nanotube in aqueous solution. J. Chem. 2013, 2013, 2371-2383.

19. Hu, Q.H.; Qiao, S.Z.; Haghseresht, F. Adsorption study for the removal of basic red dye using bentonite. Ind. Eng. Chem. Res. 2006, 45, 733-738.

20. Salman, D.D.; Ulaiwi, W.S.; Tariq, N.M. Determination the optimal conditions of methylene blue adsorption by the chicken egg shell membrane. Int. J. Poult. Sci. 2012, 11, 391-396.

21. Karima, B.; Mossab, B.L.; A-Hassen, M. Removal of methylene blue from aqueous solutions using an acid activated Algerian bentonite: Equilibrium and kinetic studies. In Proceedings of the International Renewable Energy Congress, Sousse, Tunisia, 5-7 November 2010.

22. Jain, M.; Garg, V.K.; Krishna, K. Adsorption of hexavalent chromium from aqueous medium onto carbonaceous adsorbents prepared from waste biomass. J. Hazard. Mater. 2010, 91, 949-954.

23. Han, R.P.; Zhang, J.J.; Han, P.; Wang, Y.F.; Zhao, Z.H.; Tang, M.S. Study of equilibrium, kinetic and thermodynamic parameters about methylene blue adsorption onto natural zeolite. Chem. Eng. J. 2009, 145, 496-504.

24. Xiong, L.; Yang, Y.; Mai, J.; Sun, W.; Zhang, C.; Wei, D.; Chen, Q.; Ni, J. Adsorption behavior of methylene blue onto titanate nanotubes. Chem. Eng. J. 2010, 156, 313-320.

25. Sainz-Diaz, C.I.; Griffiths, A.J. Activated carbon from solid wastes using a pilot scale batch flaming pyrolyser. Fuel 2000, 79, 1863-1871.

26. Banat, F.; Al-Asheh, S.; Al-Makhadmeh, L. Evaluation of the use of raw and activated date pits as potential adsorbents for dye containing waters. Process Biochem. 2003, 39, 193-202. 
27. Phenrat, T.; Saleh, N.; Sirk, K.; Tilton, R.D.; Lowry, G.V. Aggregation and sedimentation of aqueous nanoscale zero valent iron dispersions. Environ. Sci. Technol. 2007, 41, 284-290.

28. Zheng, T.; Zhan, J.; He, J.; Day, C.; Lu, Y.; McPerson, G.L.; Piringer, G.; John, V.T. Reactivity characteristics of nanoscale zerovalent iron-silica composites for trichloroethylene remediation. Environ. Sci. Technol. 2008, 42, 4494-4499.

29. Yuvakkumar, R.; Elango, V.; Rajendran, V.; Kannan, N. Preparation and characterization of zerovalent iron nanoparticles. Dig. J. Nanomater. Biostruct. 2011, 6, 1771-1776.

(C) 2014 by the authors; licensee MDPI, Basel, Switzerland. This article is an open access article distributed under the terms and conditions of the Creative Commons Attribution license (http://creativecommons.org/licenses/by/3.0/). 